\title{
Impact of conventional insecticides on two bollworms and their indirect effects on the ectoparasitoid, Bracon brevicornis (Wesmael) (Hymenoptera: Braconidae)
}

\author{
Mervat A. Kandil and Hemat Z. Moustafa*
}

\begin{abstract}
Background: Cotton bollworms such as Pectinophora gossypiella and Earias insulana are serious pests which destroy the cotton plant, and Bracon brevicornis is a parasitoid which attacked the larvae of bollworms.

Results: In this study, experiments were performed to investigate and evaluate the toxicity of etofenprox and chlorpyrifos insecticides against newly hatched larvae of Pectinophora gossypiella and Earias insulana. Some biological aspects of compound effects on larval and pupal duration, percentage of mortality, and percentage of adult emergence which resulted from treated newly hatched larvae were studied. The results revealed that $L C_{50}$ was 0.7 and $0.87 \mathrm{ppm}$ when P. gossypiella was treated with etofenprox and chlorpyrifos, respectively, while $\mathrm{LC}_{50}$ was 0.09 and $0.73 \mathrm{ppm}$ when E. insulana was treated with etofenprox and chlorpyrifos, respectively. The obtained results showed that the percentage of mean larval mortality was 65.0 and $63.0 \%$ for treated $P$. gossypiella, while it was 71.0 and $66.0 \%$ for treated E. insulana. The corresponding figure for pupal percentage mortality was 8.0 and $10.0 \%$ for treated P. gossypiella, but it was 5.0 and $2.0 \%$ for treated E. insulana, with etofenprox and chlorpyrifos, and a prolongation effect in larval and pupal development (total immature stage) resulted from treated both bollworms as follows: 35.5 and 32.4 days for treated P. gossypiella compared with 21.9 days in control and 34.7 and 23.2 days for treated E. insulana compared with 23.1 days in control. The indirect effect of etofenprox and chlorpyrifos on the total immature stage of Bracon brevicornis was 18.2 and 19.5 days compared with 14.3 days in control when B. brevicornis parasitized on P. gossypiella larvae while it was 19.8 and 20.6 days compared with 15.2 days when B. brevicornis parasitized on E. insulana larvae.
\end{abstract}

Conclusion: The life cycle of B. brevicornis after parasitism on P. gossypiella and E. insulana larvae treated with etofenprox and chlorpyrifos were increased than the control larvae.

Keywords: Pectinophora gossypiella, Earias insulana, Toxicity, Etofenprox and Chlorpyrifos, Indirect effect of insecticides, Bracon brevicornis

\section{Introduction}

In Egypt, up till now, the bollworms are the most important pests that attacked the cotton (Gossypium spp.); the pink bollworm, Pectinophora gossypiella (Saunders) (Lepidoptera: Gelechiidae), in many cotton-producing areas of the world, causes serious damage in cotton bolls and great loss in both quality and quantity of cotton

\footnotetext{
* Correspondence: hematzakaria@gmail.com

Plant Protection Research Institute, Agriculture Research Center, Dokki, Giza, Egypt
}

yield. The spiny bollworm, Earias insulana (Lepidoptera: Noctuidae), is a key pest of cotton. Its larvae are a major cosmopolitan pest of a wide range of crops in various parts of Egypt. It is found on all Gossypium species including cotton, Okra, and other host plants which are mainly confined to the Malvaceae and few species of Tiliaceae. It causes damage and reduces boll and cotton yield, (Kandil 2001). Up till now, some trials in the laboratory or under the environmental field used 
insecticides for controlling the bollworm pests, such as pyrethroid or phosphorus compounds.

Parasitoid wasps, Bracon brevicornis (Hymenoptera: Braconidae), being primary parasitoids, attacked the different larvae of Lepidoptera insects. Parasitoids are insects whose larvae developed by feeding on bodies of different insects, eventually resulting on the death of the host, and a single host provides all the food required for the development of the larval stage parasitoid unto pupal stage. Actually, most of the studies regarding the effects of insecticides (inclusive for pyrethroids or phosphorus) on parasitoids and other natural enemies have relied on the evaluation of acute toxicity by determination of a median lethal dose $\mathrm{LD}_{50}$ or concentration $\mathrm{LC}_{50}$ (Desneux et al. 2006 and 2007 and Kandil 2007).

The main routes of pyrethroid or phosphorus compound exposure for larvae or/and adult parasitoids are uptake after direct exposure to spray droplets and uptake of residues by contact with contaminated surfaces or food sources (Longley and Stark 1996); some authors recorded that when parasitizing or feeding on host treated with insecticide, all the stages (egg, larva, and pupa) of parasitoids are highly affected; also, the latent effect caused reductions in the longevity and fecundity when the parasitoids are exposed to insecticides during development inside or outside the host treated (Longley 1999, Ergin et al. 2007, and Kandil 2007).

This study aimed to obtain knowledge or information on the effects of conventional insecticides like pyrethroids and organophosphorus on some biological and biochemical aspects of $P$. gossypiella and Earias insulana and indirect effects on Bracon brevicornis.

\section{Material and methods}

\section{Hosts used}

\section{Pink bollworm (PBW) and spiny bollworm (SBW)}

The first instar larvae of pink bollworm $P$. gossypiella and spiny bollworm $E$. insulana used in this study was obtained from the laboratory colony of Bollworm Department, Plant Protection Research Institute; Agriculture Research Center (ARC), reared for several generations away from any contamination, with insecticides on an artificial diet as described by Rashad and Ammar (1985) and Amer (2015).

\section{The parasitoid of Bracon brevicornis}

The Bracon brevicornis was collected from infested dry cotton bolls by parasitized pink bollworm diapauses with B. brevicornis larvae at the end of cotton season from cotton fields at El-Qaliobia region, Qaha Governorate. The larvae and cocoons of Bracon associated with full-grown host were collected and reared for two generations on full-grown larvae of $P$. gossypiella and
E. insulana to adapt to the parasitoid before directing the experiment.

\section{Insecticides used}

Two insecticides of different groups were tested for their larvicidal effect, their classification are as follows:

\section{Common name: Etofenprox 30\% EC}

Trade name: Trebon 30\% EC (rate of feddan, $50 \mathrm{~cm} / \mathrm{fed}$ ). Chemical name: 2-(4-Ethoxyphenyl)-2-methylpropyl 3phenoxybenzyl ether.

\section{Common name: Chlorpyrifos $48 \% \mathrm{EC}$}

Trade name: Dora 48\% EC (rate of feddan, 1 l/fed). Chemical name: Diethoxy-sulfanylidene-(3,5,6-trichloropyridin-2-yl)oxy- $\lambda 5$-phosphane.

\section{Procedure}

To study the larvicidal activity of etofenprox and chlorpyrifos against first instar larvae of $P$. gossypiella or E. insulana, serial concentrations in water were prepared. Six concentrations $(0.466,0.233,0.116,0.58,29$, and $0.14 \mathrm{ppm})$ for etofenprox and five concentrations $(4.6,2.3,1.105,0.65$, and $0.32 \mathrm{ppm})$ for chlorpyrifos were freshly prepared for the stock solution of each compound ( $1 \mathrm{ml} / 1 \mathrm{l}$ water).

\section{Determine the toxicity of tested compounds on first instar larvae of $P$. gossypiella and $E$. insulana}

To determine the toxicity of two tested compounds against first instar larvae of $P$. gossypiella and E. insulana, the different concentrations of each tested compound were sprayed on the surface of an artificial diet in Petri dishes. Thirty first instar larvae of the PBW or SBW for first instar were allowed to feed on the treated diet for each compound and were kept under constant conditions of $26.0 \pm 1.0^{\circ} \mathrm{C}$ and $75.0 \pm 5.0 \% \mathrm{RH}$. After 1 day for etofenprox or chlorpyrifos treatment, the dead larvae were counted to represent acute toxicity of the two tested compounds. The percentage of larval mortality was calculated by Abbot's formula (1925). Three replicates were used in the experiments.

\section{Biological aspect studies}

For the same biological aspects studies, three replicates of 40 tubes, each tube $(2 \mathrm{~cm} \times 7.5 \mathrm{~cm})$ containing $4.0 \mathrm{~g}$ of diet, were used. Alive larvae that no effect which resulted from newly hatched larvae treated with $\mathrm{LC}_{50}$ of etofenprox and chlorpyrifos for $24 \mathrm{~h}$ were transferred individually to the diet tubes by camel hair brush. The same was done with the newly hatched larvae which resulted from control eggs. The tubes were capped with 
cotton and kept in laboratory under the previous conditions in an incubator with untreated diet and inspected daily until pupation. Pupae resulted from each treatment were removed from all tubes and placed in clean tubes till adult emergence. Some biological aspects such as larval malformation, larval and pupal durations, percentage of adult emergence, malformation and sex ratio, fecundity, and fertility were determined.

\section{Biochemical assays}

The assays were done at the Physiological Department of the Plant Protection Research Institute (P.P.R.I.). Samples of $P$. gossypiella and E. insulana treated and control larvae were collected after 14 days from different treatments and were homogenized in distilled water. The homogenates were centrifuged at $5000 \mathrm{rpm}$ at $5.0{ }^{\circ} \mathrm{C}$. The supernatants were kept in deep freezer at $-20.0{ }^{\circ} \mathrm{C}$ till use for biochemical assays.

The colorimetric determination of total soluble protein, total lipids, and carbohydrate in total homogenate of $E$. insulana adults that were estimated by the method of Bradford (1976), Knight et al. (1972), and Cromppton and Birt (1967) was done.

\section{Reared parasitoid B. brevicornis on host larvae treated}

To evaluate the effect of compounds on the progeny of the tested parasitoid, laboratory experiments were directed under controlled conditions $\left(26.0 \pm 1.0 \mathrm{C}^{\circ}\right.$ and $60.0-65.0 \% \mathrm{RH})$.

Newly emerged adults of the parasitoid were sexed $\left(10\right.$ ㅇ and $\left.10{ }^{\gamma}\right)$ and kept in glass jars $(1 / 2 \mathrm{~kg})$ with several droplets of honey bee being streaked on the surface of the glass jars as a source of food for the female wasps. Ten individually treated larvae from each host used ( $P$. gossypiella or E. insulana (treated full grown larvae)) were offered daily to female parasitoids inside a glass jar; each glass jar was covered with muslin cloth and daily examination/glass jar. The daily parasitized host insect/ glass jar was carefully transferred to Petri dishes. The number of paralyzed and parasitized host and the number of laid eggs by the female wasp (on different hosts) were recorded daily and kept under the same conditions until the parasitoid death. Also, the percentage of hatchability and adult emergence were estimated. From the recorded data, the preferred host and/or age could be determined.

To determine other biological aspects of the parasitoid, 60 eggs of the parasitoid were collected for each tested host $P$. gossypiella, and E. insulana (larvae carried the parasitoid eggs) were daily examined to estimate the incubation period of eggs, larval and cocoon duration, and adult emergence. All experiments were carried out under laboratory conditions at $26.0 \pm 1.0^{\circ} \mathrm{C}$ and 65.0 $70.0 \% \mathrm{RH}$.

\section{Statistical analysis}

All the recorded data values were statistically analyzed with one-way analysis of variance (ANOVA) $(P<0.05 \%)$ (Snedecor 1952) and Duncan's multiple range test of means (Duncan 1955) being used. The analysis was conducted to estimate $\mathrm{LC}_{50}$ and $\mathrm{LC}_{90}$ values with their fiducial limits by Probit (proban) analysis software according to Finny (1971).

\section{Results}

Toxicity of etofenprox and chlorpyrifos were recorded under laboratory conditions. The $\mathrm{LC}_{50}$ and $\mathrm{LC}_{90}$ values were summarized in Table 1. It was noticed that etofenprox was more toxic and effective on both $P$. gossypiella and $E$. insulana where the $\mathrm{LC}_{50}$ values were 0.07 and $0.09 \mathrm{ppm}$, respectively, than chlorpyrifos where the $\mathrm{LC}_{50}$ values were 0.87 and $0.73 \mathrm{ppm}$, for the two insects respectively.

The percent of mortality and duration of larval, pupal, and total immature stages resulted from treated newly hatched larvae of $P$. gossypiella and $E$. insulana with $\mathrm{LC}_{50}$ value of etofenprox and chlorpyrifos are shown in Table 2 .

The mean larval mortality percentages were 65.00 and $63.00 \%$ respectively compared with $3.00 \%$ in control for $P$. gossypiella newly hatched larvae treated with etofenprox and chlorpyrifos while the corresponding figure for $E$. insulana treated with the same two insecticides percent of mortality were 71.00 and $66.00 \%$ respectively compared with $4.00 \%$ in control. Pupal mortality percentages and malformed were 8.00 and $10.00 \%$ in the case of treated $P$. gossypiella with etofenprox and chlorpyrifos but decreased to 5.00 and $2.00 \%$ after treated E. insulana. Total mortality and malformed were 78.00 and $75.00 \%$ when treated P. gossypiella with the same two insecticides compared with $6.00 \%$ in control but were 76.00 and $68.00 \%$ after treated E. insulana with etofenprox and chlorpyrifos compared with $8.00 \%$ in control.

Etofenprox and chlorpyrifos prolonged the duration of larval stage, significantly. These periods were estimated to be 23.50 and 19.00 days/larvae, respectively, when treated P. gossypiella compared with 14.30 days in control and 21.40 and 17.30 days/larvae, respectively, when treated E. insulana compared with 15.30 days in control. Also, the two used insecticides caused an increase in pupal period, by 12.00 and 13.40 days/pupa, respectively, compared to 7.60 days in control of $P$. gossypiella and 13.00 and 11.90 days/pupa when treated E. insulana. The total immature stage of $P$. gossypiella were 35.50 and 32.40 days, which resulted from newly hatched larvae treated with etofenprox and chlorpyrifos, respectively, compared with 21.90 days in control, while total immature stage of E. insulana were 34.70 and 23.20 days after being treated with etofenprox and chlorpyrifos compared with 23.1 days in control. 
Table 1 Toxicological evaluation of etofenprox and chlorpyrifos against newly hatched larvae of P. gossypiella and E. insulana under laboratory conditions

\begin{tabular}{|c|c|c|c|c|}
\hline \multirow[t]{2}{*}{ Insect } & \multirow{2}{*}{$\begin{array}{l}\text { Compounds } \\
\text { used }\end{array}$} & \multicolumn{3}{|c|}{ Toxicity, (95\% Confidence limits) } \\
\hline & & $\mathrm{LC}_{50}(\mathrm{ppm})$ & $\mathrm{LC}_{90}(\mathrm{ppm})$ & Slope \pm SE \\
\hline \multirow[t]{2}{*}{ P. gossypiella } & Etofenprox & $0.07(0.053-0.09)$ & $0.39(0.27-0.68)$ & $1.71 \pm 0.23$ \\
\hline & Chlorpyrifos & $0.87(0.59-1.22)$ & $6.22(3.60-17.90)$ & $1.50 \pm 0.27$ \\
\hline \multirow[t]{2}{*}{ E. insulana } & Etofenprox & $0.09(0.07-0.11)$ & $0.30(0.23-0.43)$ & $2.46 \pm 0.27$ \\
\hline & Chlorpyrifos & $0.73(0.52-0.95)$ & $3.26(2.24-6.16)$ & $1.97 \pm 0.32$ \\
\hline
\end{tabular}

\section{Indirect toxicity of on Bracon brevicornis}

Indirect toxic effects of etofenprox and chlorpyrifos on immature stages of parasitoid B. brevicornis at all periods of parasitism were obviously different than that of the control at different stages of development (Table 3).

Data in Table 3 showed the incubation period of $B$. brevicornis eggs that parasitized on $P$. gossypiella and E. insulana which were previously treated as newly hatched larvae with the $\mathrm{LC}_{50}$ values of etofenprox and chlorpyrifos. As for P. gossypiella, it was 2.8 and 2.7 days, respectively compared with 2.3 days for control, and was 2.9 and 2.7 days in the case of E. insulana compared with 2.6 days for control.

Larval stage of B. brevicornis lasted 10.9 and 11.3 days when reared on full-grown larvae of $P$. gossypiella previously treated as newly hatched larvae with the $\mathrm{LC}_{50}$ values of etofenprox and chlorpyrifos, respectively, compared with 8.9 days for control. The corresponding figure for E. insulana was 12.9 and 13 days, respectively, compared with 9.3 days for control, whereas the pupal period showed different from the control one which were 7.3 and 8.2 days/pupa which resulted from that reared on $P$. gossypiella treated with etofenprox and chlorpyrifos, respectively, compared with 5.4 days in control, while pupal periods were 6.9 and 7.6 days/pupa when E. insulana was treated with etofenprox and chlorpyrifos compared with 5.9 days in control.
The analysis of variance results are arranged in Table 3. The two tested compounds caused a highly significant reduction in the percentage of the adult parasitoid emergence; it was 61 and $56 \%$ when $P$. gossypiella was treated with etofenprox and chlorpyrifos compared with $94 \%$ in control, while adult parasitoid emergence when reared on E. insulana treated with etofenprox and chlorpyrifos, respectively, was 33 and $49 \%$ compared with $94 \%$ in control.

Generally, the parasitoid B. brevicornis was highly affected when reared on treated larvae of $P$. gossypiella or E. insulana; the different immature stages require the time increased from 2-3 days for completing the developmental stages than the control.

The results in Table 4 showed reduction of percent in protein, lipids, and carbohydrates of fourth instar larvae of P. gossypiella and E. insulana which resulted from treated newly hatched larvae. Etofenprox and chlorpyrifos treatments on $P$. gossypiella reduced the total protein content to -38.14 and $-52.80 \%$, respectively compared with the control larvae, while the reduction were 39.93 and $24.44 \%$ respectively when treated E. insulana.

Etofenprox and chlorpyrifos treatments on $P$. gossypiella reduced lipids to -41.98 and $-50.17 \%$, respectively, compared with the control larvae, while the reduction was 7.97 and $55.81 \%$ respectively when treated E. insulana. The total carbohydrates content of fourth instar larvae of $P$. gossypiella and E. insulana decreased

Table 2 Effect of tested compounds on different stages of P. gossypiella and E. insulana treated as newly hatched larvae

\begin{tabular}{|c|c|c|c|c|c|c|c|c|}
\hline \multicolumn{2}{|c|}{ Biological aspects } & \multirow[t]{2}{*}{ Conc. } & \multicolumn{2}{|l|}{ Larval stage } & \multicolumn{2}{|l|}{ Pupal stage } & \multirow{2}{*}{$\begin{array}{l}\text { \% total } \\
\text { mortality } \\
\text { and } \\
\text { Malformed }\end{array}$} & \multirow{2}{*}{$\begin{array}{l}\text { Total } \\
\text { immature } \\
\text { stage }\end{array}$} \\
\hline & & & $\%$ mortality & Time in days & \%mortality and malformed & Time in days & & \\
\hline \multirow[t]{2}{*}{ P. gossypiella } & Etofenprox & 0.07 & 65.00 & $23.50 \pm 2.10$ & 8.00 & $12.00 \pm 1.10$ & 78.00 & $35.50 \pm 2.10$ \\
\hline & Chlorpyrifos & 0.87 & 63.00 & $19.00 \pm 1.50$ & 10.00 & $13.40 \pm 0.90$ & 75.00 & $32.40 \pm 2.40$ \\
\hline \multicolumn{2}{|l|}{ Control } & 0.00 & 3.00 & $14.30 \pm 0.90$ & 5.00 & $7.6 \pm 0.3$ & 8.00 & $21.90 \pm 1.90$ \\
\hline \multicolumn{2}{|l|}{$\mathrm{LSD}_{05}$} & - & 6.82 & 3.12 & 1.99 & 2.22 & 2.17 & 2.40 \\
\hline \multicolumn{2}{|l|}{$F$ value } & - & 319.2 & 28.68 & 469.9 & 24.04 & 364.2 & 120.87 \\
\hline \multirow[t]{2}{*}{ E. insulana } & Etofenprox & 0.09 & 71.00 & $21.40 \pm 1.80$ & 5.00 & $13.0 \pm 1.20$ & 76.00 & $34.70 \pm 1.30$ \\
\hline & Chlorpyrifos & 0.73 & 66.00 & $17.30 \pm 0.90$ & 2.00 & $11.90 \pm 1.30$ & 68.00 & $29.20 \pm 2.40$ \\
\hline \multicolumn{2}{|l|}{ Control } & 0.00 & 4.00 & $15.30 \pm 0.90$ & 4.00 & $7.80 \pm 0.30$ & 8.00 & $23.10 \pm 0.90$ \\
\hline \multicolumn{2}{|l|}{$\mathrm{LSD}_{05}$} & - & 3.88 & 1.62 & 0.24 & 1.96 & 2.04 & 2.13 \\
\hline \multicolumn{2}{|l|}{$F$ value } & - & 1129.08 & 23.87 & 411.3 & 21.97 & 28.12 & 144.25 \\
\hline
\end{tabular}


Table 3 Indirect effect of tested compounds on progeny (immature stage) of Bracon brevicornis reared on full-grown larvae of $P$. gossypiella and E. insulana treated as newly hatched larvae

\begin{tabular}{|c|c|c|c|c|c|c|c|}
\hline \multicolumn{2}{|l|}{ Treated host } & \multicolumn{6}{|c|}{ Progeny of Bracon brevicornis } \\
\hline & & \multicolumn{3}{|c|}{ Duration of Bracon brevicornis immature stages (days $\pm \mathrm{SE}$ ) } & \multirow{2}{*}{$\begin{array}{l}\text { Total immature } \\
\text { stage } \pm \text { SE }\end{array}$} & \multirow{2}{*}{$\begin{array}{l}\text { Life cycle } \\
\pm \text { SE }\end{array}$} & \multirow{2}{*}{$\begin{array}{l}\% \text { emergence } \\
\text { of adults }\end{array}$} \\
\hline & & Eggs & Larvae & Pupae & & & \\
\hline \multirow[t]{2}{*}{ P. gossypiella } & Etofenprox & $2.8 \pm 0.10$ & $10.9 \pm 0.6$ & 7.3. \pm 0.3 & $18.2 \pm 0.8$ & $21.0 \pm 1.6$ & 61.00 \\
\hline & Chlorpyrifos & $2.7 \pm 0.2$ & $11.3 \pm 0.33$ & $8.2 \pm 0.2$ & $19.5 \pm 1.3$ & $22.2 \pm 1.6$ & 56.00 \\
\hline Control & & $2.3 \pm 0.2$ & $8.9 \pm 0.6$ & $5.4 \pm 0.2$ & $14.3 \pm 0.9$ & $16.6 \pm 0.2$ & 94.00 \\
\hline $\mathrm{LSD}_{05}$ & & 0.13 & 0.43 & 0.35 & 1.22 & 1.37 & 2.49 \\
\hline$F$ value & & 47.4 & 198.79 & 166.92 & 0.80 & 339.5 & 551.09 \\
\hline \multirow[t]{2}{*}{ E. insulana } & Etofenprox & $2.9 \pm 0.2$ & $12.9 \pm 0.32$ & $6.9 \pm 0.2$ & $19.8 \pm 0.6$ & $22.7 \pm 2.6$ & 33.00 \\
\hline & Chlorpyrifos & $2.7 \pm 0.1$ & $13.0 \pm 0.70$ & $7.6 \pm 0.3$ & $20.6 \pm 1.2$ & $23.3 \pm 2.1$ & 49.00 \\
\hline Control & & $2.6 \pm 0.2$ & $9.3 \pm 0.4$ & $5.9 \pm 0.2$ & $15.2 \pm 0.6$ & $17.8 \pm 0.2$ & 92.00 \\
\hline $\mathrm{LSD}_{05}$ & & 0.20 & 0.36 & 0.42 & 1.89 & 2.01 & 2.31 \\
\hline$F$ value & & 1.08 & 95.30 & 29.30 & 80.59 & 349.60 & 856.78 \\
\hline
\end{tabular}

to -42.36 and -35.99 and -40.00 and -45.10 , respectively, in etofenprox and chlorpyrifos treatments presented in Table 4.

\section{Discussion}

Many authors studied the effect of insecticides on natural enemies; Hooshang et al. (2009) assessed the effects of sub-lethal dose of profenofos, spinosad, and thiodicarb on demographic and biological parameters of Habrobracon hebetor. Sex ratio of $H$. hebetor was highly affected by insecticides. Profenofos had moderately toxic effect on wasps. Also, Saber et al. (2005) reported that deltamethrin had no significant effects on biological parameters of Trissolcus wasps, while Armenta et al. (2003) reported that organophosphorus compound have adverse effects on insect natural enemies on maize. Indirect toxicity of insecticides to the larval parasitoid
$B$. hebetor indicated that the larval and pupal periods were increased in times than the control at all periods of parasitism, and some authors have the same finding with our results; Anne et al. (2001) and Khan et al. (2005 and 2009) reported that the pesticides' effect on the parasitoid $B$. hebetor causes increase in the mortality and duration of immature stages. Also, Faal (2010) found that chlorpyrifos was highly toxic and affected $H$. hebetor. And Ebeid et al. (2017) showed the acute toxicity and the effects of profenofos, cyfluthrin, and the IGR on the activity of the larval parasitoid, $B$. hebetor. Cyfluthrin was the most toxic one which was dangerous on all life stages of $B$. hebetor, influencing the number of laid eggs by the parasitoid and percent of pupation and leading to failure of adult emergence. Mbata and Warsi (2019) stated that Habrobracon hebetor (Say) (Hymenoptera: Braconidae) are important parasitoids. Host searching ability and reproductive

Table 4 Effect of tested compounds on physiological of two hosts, full-grown P. gossypiella and E. insulana (resulted from treated newly hatched larvae)

\begin{tabular}{|c|c|c|c|c|c|c|c|c|}
\hline \multicolumn{2}{|c|}{ Biological aspects } & \multirow[t]{2}{*}{ Conc. } & \multicolumn{2}{|c|}{ Protein (mg/g.b.wt) } & \multicolumn{2}{|c|}{ Lipids (mg/g.b.wt) } & \multicolumn{2}{|c|}{ Carbohydrates(mg/g.b.wt) } \\
\hline & & & Mean \pm S.E & $\%$ reduction & Mean \pm S.E & \%reduction & Mean \pm S.E & $\%$ reduction \\
\hline \multirow[t]{2}{*}{ P. gossypiella } & Etofenprox & 0.07 & $14.6 \pm 1.22$ & -38.14 & $17.0 \pm 0.9$ & -41.98 & $20.3 \pm 0.8$ & -29.75 \\
\hline & Chlorpyrifos & 0.87 & $11.14 \pm 0.8$ & -52.80 & $14.6 \pm 1.2$ & -50.17 & $18.5 \pm 1.8$ & -35.99 \\
\hline \multicolumn{3}{|l|}{ Control } & $23.6 \pm 1.3$ & 0.00 & $29.3 \pm 1.7$ & 0.00 & $28.9 \pm 1.4$ & 0.00 \\
\hline \multicolumn{3}{|l|}{$\mathrm{LSD}_{05}$} & 2.57 & 0 & 2.20 & 0 & 2.95 & 0 \\
\hline \multicolumn{3}{|l|}{$F$ value } & 75.61 & 0 & 152.45 & 0 & 42.19 & 0 \\
\hline \multirow[t]{2}{*}{ E. insulana } & Etofenprox & 0.09 & $17.6 \pm 1.2$ & -39.93 & $28.53 \pm 0.98$ & -7.97 & $15.3 \pm 0.98$ & -40.00 \\
\hline & Chlorpyrifos & 0.37 & $22.14 \pm 1.4$ & -24.44 & $13.7 \pm 1.1$ & -55.81 & $14.0 \pm 1.7$ & -45.10 \\
\hline \multicolumn{3}{|l|}{ Control } & $29.3 \pm 0.9$ & 0.00 & $31.0 \pm 1.5$ & 0.00 & $25.5 \pm 1.8$ & 0.00 \\
\hline \multicolumn{3}{|l|}{$\mathrm{LSD}_{05}$} & 1.93 & 0 & 2.75 & 0 & 1.85 & 0 \\
\hline \multicolumn{3}{|l|}{$F$ value } & 110.32 & 0 & 141.76 & 0 & 133.00 & 0 \\
\hline
\end{tabular}

Values are mean $\pm \mathrm{SE}$ of three replicates

Reduction $(\%)=[($ mean values of treatment - mean values of control $) /$ mean values of control $] \times 100$ 
performances of $H$. hebetor depend on a wide range of factors, such as host species, commodities, and environmental conditions.

The result of the tested enzymes agrees with Kandil et al. (2013a, b) who found that the chlorfluazuron caused high reduction in total lipid, protein, and carbohydrates in full-grown larvae of $P$. gossypiella, and Said et al. (2017) recorded that IGRs caused high difference in the total protein and lipid for P. gossypiella larvae than the control.

\section{Conclusion}

From all data, it can be concluded that there were relationships between the effect of the two treatments on some biological and biochemical of hosts, P. gossypiella and E. insulana, and reared the parasitoid on the treated hosts, and it caused to elongate the time duration for the two hosts and parasitoid reared on host treated with reduction in adult parasitoid results.

\section{Abbreviations}

P.P.R.I.: Plant Protection Research Institute; PBW: Pink bollworm; SBW: Spiny bollworm

\section{Acknowledgements}

Not available

\section{Authors' contributions}

All authors had equal contribution and read and approved the final manuscript.

\section{Funding}

Not available

Availability of data and materials

All data in the tables are so clear, and these numbers are the raw data.

Ethics approval and consent to participate

Not available

\section{Consent for publication}

Available

\section{Competing interests}

The authors declare that they have no competing interests.

Received: 6 November 2019 Accepted: 10 December 2019

Published online: 26 December 2019

\section{References}

Amer AEA (2015). Economic artificial diets for rearing spiny bollworm, Eariasinsulana (Boisd.) (Lepidoptera: Noctuidae). J Plant Prot Pathol, Mansoura Univ., Vol. 6 (3):527 - 534.

Anne A, Anne MC, Jean PN, Jean PA (2001) Selectivity assessment of chlorfenvinphos reevaluated by including physiological and behavioral effects on an important beneficial insect. Environ Toxicol Chem 20(11):2530-2536

Armenta R, Martínez AM, Chapman J, Magallanes R, Goulson D (2003) Impact of a nucleopolyhedrovirus bioinsecticide and selected synthetic insecticides on the abundance of insect natural enemies on maize in Southern Mexico. J Econ Entomol 96:649-661

Bradford MM (1976) A rapid and sensitive method for the quantization of microgram quantities of protein utilizing the principle of protein dye binding. Ann Biochem 72:248-254
Cromppton M, Birt LM (1967) Changes in the amounts of carbohydrate, phosphagen, and related copounds during the metamorphosis of the blowfly, Lucilia cuprina. J Insect Physiol 13:1575-1595

Desneux N, Decourtye A, Delpuech JM (2007) The sub-lethal effects of pesticides on beneficial arthropods. Ann Rev Entomol 52:81-106

Desneux N, Denoyelle R, Kaiser L (2006) A multi-step bioassay to assess the effect of the deltamethrin on the parasitic wasp Aphidius ervi. Chemosphere 65:1697-1706

Duncan DB (1955) Multiple range and multiple F test. Biometrics 11:1-42

Ebeid AR, Elbehery HH, Farag NA, Gesraha MA (2017) Toxicity of some insecticides on the hymenopteran parasitoid, Bracon Hebetor (Hymenoptera: Braconidae). Eur J Sustainable Dev 6(4):72-80

Ergin E, Er A, Uçkan F, Rivers DB (2007) Effect of cypermethrin exposed hosts on egg-adult development time, number of offspring, sex ratio, longevity, and size of Apanteles galleriae Wilkinson (Hymenoptera: Braconidae). Belgian J Zool 137(1):27-31

Faal-M AH (2010). The sub-lethal effects of chlorpyrifos and fenpropatrin on the biological parameters and functional response of Habrobracon hebetor Say (Hymenoptera:Braconidae) in the laboratory condition. M.Sc. Thesis, Shahid Chamran Ahvaz University, Khozestan, Iran, 128 pp.

Finny DJ (1971) Probit - analysis, 3rd edn. Cambridge University Press, Lnondn Hooshang RD, Mir Jalil H, Ghadir NG, Moosa S (2009) Sublethal effects of some conventional and biorational insecticides on ectoparasitoid, Habrobracon hebetor Say (Hymenoptera: Braconidae). J Entomol 6(2):82-89

Kandil M.A. (2001). Studies on the predaceous and parasitic insects on the pink and spiny bollworm. Ph.D. Thesis, Faculty of Agriculture, Benha Branch, Zagazig University.

Kandil MA (2007). Effect of profenofous and diflubenzuron on Pectinophora gossypiella (Saunders) and its parasitoid Dibrachys cavus (Walker). Bulletin of the Entomological Society of Egypt, Economic Series. 33:77-92.

Kandil MA, Ahmed AF, Moustafa HZ (2013b) Toxicological and biochemical studies of lufenuron, chlorfluazuron and chromafenozide against Pectinophora gossypiella (Saunders). Egypt Acad J Biol Sci 4(1):37-47

Kandil MA, Salem MS, Adly AM (2013a) Biological and biochemical changes in pink bollworm, Pectinophora gossypiella after treatment with Hexaflumuron and Chlorfluazuron. Ann Agric Sci Moshtohor 51(4):427-432

Khan RR, Ashfaq M, Ahmed S, Sahi ST (2009) Mortality responses in Bracon hebetor (Say) (Braconidae: Hymenoptera) against some new chemistry and conventional insecticides under laboratory conditions. Pak J Agric Sci 46(1):30-35

Khan RR, Ashfaq M, Rana SHA (2005) Some studies on the toxicity of conventional and new chemistry insecticides against Bracon hebetor Say (Hym.: Braconidae) under laboratory conditions. Pak Entomol 27(1):19-21

Knight JA, Anderson S, Rawle JM (1972) Chemical basis of the sulfo- phosphovanillin reaction for estimating total serum lipids. Clin Chem 18:199-202

Longley M (1999) A review of pesticide effect upon immature aphid parasitoids within mummified hosts. Int J Pest Manag 45(2):139-145

Longley M, Stark JD (1996) Analytical techniques for quantifying direct, residual and oral exposure of an insect parasitoid to an organophosphate insecticide. Bull Environ Contam Toxicol 57:683-690

Mbata GN, Warsi S (2019) Habrobracon hebetor and Pteromalus cerealellae as tools in post-harvest integrated pest management. Insects 10(4):85-96

Rashad AM, Ammar ED (1985) Mass rearing of the sping bollworm, E. insulana (Boisd.) on semi-artificial diet. Bull Entomol Soc Egypt Econ Ser 65:239-244

Saber M, Hejazi MJ, Kamali K, Moharramipour S (2005) Lethal and sublethal effects of fenitrothion and deltamethrin residues on the egg parasitoid Trissolcus grandis (Hymenoptera: Scelionidae). J Econ Entomol 98:35-40

Said MS, Abd El-Raheem AM, Kandil MA (2017) Biochemical effects of insect growth regulator, teflubenzuron on Pectinophora gossypiella and Coccinella undecimpunctata. Menoufia J Plant Prot 2:139-152

Snedecor GW (1952). Statistical methods 5th Ed, lowa State College New York.

\section{Publisher's Note}

Springer Nature remains neutral with regard to jurisdictional claims in published maps and institutional affiliations. 